\title{
The Microenvironment within and Pollen Transmission through Polyethylene Sorghum Pollination Bags
}

\author{
Dennis C. Gitz ${ }^{1}$, Jeffrey T. Baker ${ }^{2}$, Zhanguo Xin ${ }^{3}$, John J. Burke³, Robert J. Lascano \\ ${ }^{1}$ United States Department of Agriculture-Agricultural Research Service ${ }^{\#}$, Wind Erosion and Water \\ Conservation Unit, Lubbock, Texas, USA \\ ${ }^{2}$ United States Department of Agriculture-Agricultural Research Service, Wind Erosion and Water \\ Conservation Unit, Big Spring, Texas, USA \\ ${ }^{3}$ United States Department of Agriculture-Agricultural Research Service, Plant Stress and Germplasm \\ Development Unit, Lubbock, Texas, USA \\ Email: ${ }^{*}$ dennis.gitz@ars.usda.gov
}

Received 13 January 2015; accepted 27 January 2015; published 30 January 2015

Copyright (C) 2015 by authors and Scientific Research Publishing Inc.

This work is licensed under the Creative Commons Attribution International License (CC BY). http://creativecommons.org/licenses/by/4.0/

(c) (i) Open Access

\begin{abstract}
Bird damage is a problem in sorghum breeding and germplasm maintenance operations. Paper pollination bags are damaged by rain and provide minimal deterrent to birds. Earlier we reported upon bird resistance of spun polyethylene pollination bags. Herein, we report the potential for pollen transmission through, and the microenvironment within, hard form (HfT) and soft form (SfT) spun polyethylene pollination bags as compared to traditional Paper pollination bags. Within Paper pollination bags morning temperatures were $10^{\circ} \mathrm{C}-15^{\circ} \mathrm{C}$ above ambient and high temperature excursions as high as $45^{\circ} \mathrm{C}$ were measured. Heating in $\mathrm{Sft}$ and $\mathrm{HfT}$ was $25 \%$ and $50 \%$ that of Paper, respectively. Temperature differences between bags were attributed to differences in albedo and air permeability of the bag materials. No difference in pollen transmission through Paper and HfT was found. Although SfT allowed $35 \%-40 \%$ wind borne pollen through the pores as compared to controls, male sterile plants covered with SfT produced only 30 seeds/panicle, about 1\% of a self-pollinating fertile plant. Our results suggested that SfT could adequately reduce or eliminate cross-pollination in self-pollinating plants while maintaining near ambient environmental conditions.
\end{abstract}

\section{Keywords}

\section{Sorghum, Breeding, Pollination Bags, Bird Damage}

*Corresponding author.

"USDA is an equal opportunity provider and employer.

How to cite this paper: Gitz, D.C., Baker, J.T., Xin, Z.G., Burke, J.J. and Lascano, R.J. (2015) The Microenvironment within and Pollen Transmission through Polyethylene Sorghum Pollination Bags. American Journal of Plant Sciences, 6, $265-274$. 


\section{Introduction}

Sorghum (Sorghum bicolor L.) races exhibit considerable morphological and genetic diversity. There are tens of thousands of landraces, mutant genotypes, classical cultivars, and modern commercial hybrids, not to mention the closely related species that could be exploited for inclusion in classical breeding or in germplasm maintenance operations. The United States sorghum germplasm collection alone has more than 40,000 entries, and many other collections exist [1]. Classical breeding and germplasm collection maintenance operations require maximal genetic diversity per unit land area. This is done by reducing plot size at the expense of limiting the numbers of individuals of a given genotype. As the number of plants of a genotype decreases, preventing the loss of a single plant becomes more important.

Bird damage to developing sorghum seeds is a problem worldwide [2]. In sorghum nurseries where very few plants of a given genotype are grown in small plots, consumption of even a few plants' seed production by birds represents a considerable loss. Bird damage is a continuing problem in sorghum nursery operations conducted at the USDA-ARS location in Lubbock, TX. Attempts to protect developing seeds from damage have traditionally been by covering the developing panicles with heavy weather resistant Paper pollination bags. Such attempts have been of limited effectiveness. Birds simply tear the Paper to access the developing grain underneath. It appeared that the birds subsequently become conditioned and associate Paper pollination bags with food.

Earlier, we described the resistance of sorghum pollination bags fabricated from white spun polyethylene fiber to bird damage [3]. These bags practically eliminated seed loss to birds and were handled in the field as traditional Paper bags. Herein we further describe the performance of spun polyethylene pollination bags as compared to Paper pollination bags. The purpose of the present work was to 1) compare the microenvironments experienced by developing sorghum panicles under pollination bags fabricated from different materials, 2) to compare the potential for out crossing through bags of different materials, and 3) to examine the effect of different bag materials on seed yield in sorghum bagged at anthesis and allowed to self pollinate.

\section{Materials and Methods}

\subsection{Plant Material and Culture}

Sorghum seeds were planted in the field at the USDA nursery in Lubbock, TX ( $33^{\circ} 35^{\prime} 38.00^{\prime \prime} \mathrm{N}, 101^{\circ} 54^{\prime} 10.50^{\prime \prime} \mathrm{W}$, $960 \mathrm{~m}$ above sea level) on day of year (DOY) 16. Three sorghum lines were used in the experiments: Pioneer 84G62-N271, ATx623, and BTx623 [4]. Pioneer ${ }^{1}$ 84G62-N271, a hybrid commonly used in the region in commercial production settings, was used in the microenvironmental studies. ATx623 is a male sterile line that was used alongside BTx623 as a bioindicator of pollen transmission. The soil profile was saturated prior to planting by furrow irrigation. Seeds were planted into raised beds spaced at $1 \mathrm{~m}$ oriented north-south at a rate of 20 seeds $\cdot \mathrm{m}^{-1}$ and the plants thinned to 10 seeds $\cdot \mathrm{m}^{-1}$ after emergence. To ensure even emergence and development along and across the plots the beds were surface drip irrigated after planting and during vegetative stages of growth. Irrigation was halted at anthesis. The soil at the Lubbock USDA location is an Amarillo fine sandy loam (fine-loamy, mixed, superactive, thermic aridic Paleustalfs).

\subsection{Pollination Bags}

At boot, and shortly before anthesis, the developing sorghum panicles were covered with pollination bags. Three types of bags were used: Traditional Paper (Seedburo Equipment Co., Des Plaines, IL) pollination bags (Paper), and bags fabricated from either hardform (HfT) or softform (SfT) Tyvekspunbond polyethylene fiber sheet (Tyvek Homewrap, DuPont Corp., Wilmington DE). The HfT was of the type designed and marketed as a vapor barrier for residential building construction and readily available from many local building supply stores. The SfT was a material used for disposable clothing and was hot pin perforated with $0.13-0.51 \mathrm{~mm}$ holes. Bag fabrication is detailed elsewhere [3]. Briefly, a roll of material was cut into $32 \times 38 \mathrm{~cm}$ pieces folded in half and sewn leaving one short edge open. The resulting $15 \mathrm{~cm} \times 37 \mathrm{~cm}$ bags were turned inside-out prior to use and used as traditional Paper pollination bags.

\subsection{Micro-Environment within Bags}

Temperature and relative humidity (RH) within the bags covering developing panicles/seeds were measured

${ }^{1}$ Mention of trade names or commercial products in this publication is solely for the purpose of providing specific information and does not imply recommendation or endorsement by the U.S. Department of Agriculture. 
with solid state sensors (Model HMP60 Temperature and Relative Humidity Probe, Campbell Scientific, Logan UT). To provide support for the sensors, hold them in proximity to the developing panicles, and to prevent them from leaning against the bag itself each sensor was fastened to a thin plastic stake, which was trimmed to the height of the panicle and tied to the main stem of each plant. Pollination bags were then placed over the entire arrangement, the bag opening folded around the stem, and the opening stapled so the bag would not come off in high winds. Four pollination bags of each material type were instrumented in the hybrid, Pioneer 84G62-N271 plot. The ambient temperature and RH was measured with two additional sensors in Gill radiation shields at panicle height. Data were collected every $5 \mathrm{~s}$ and 5 or 15 minutes averages, calculated, and stored. For presentation $\mathrm{RH}$ and dewpoint are plotted for three consecutive days. The RH was presented because this is used in most seed storage and development reports. Dewpoint inside bags was calculated [5] to reduce apparent temperature dependent variation in $\mathrm{RH}$ and so more accurately reflect water content of the atmosphere within the bags. Moreover, atmospheric dewpoint changes very little as compared to RH so it was thought that this would more accurately reflect differential moisture permeability from the bag interior to the atmosphere. Down welling solar irradiance and other ambient environmental conditions were recorded by a nearby weather station (http://www.lbk.ars.usda.gov/WEWC/weather-pswc-data.aspx) located 175 m east of the sorghum plots.

\subsection{Pollen Permeability}

A direct measure of the potential for cross-pollination under the three bag types was made by planting a row of a cytoplasmic male sterile sorghum variety, ATx623, between rows of the fertile counterpart, BTx623, and covering the developing panicles with pollination bags made of the different materials shortly after boot. As the panicles emerged from the sheaths they were covered with bags fabricated from the different materials in a repeating sequence, Paper, HfT, SfT, Paper, HfT..., until the bag supply was expended. The BTx623 was used as a pollen source in addition to the other sorghums in the nursery because it flowers at about the same time as its male sterile counterpart, ATx623. Pollen transmission through the differing bag materials was additionally assessed by covering "pollen traps" with the different bags [6]. A pollen trap was made by very thinly coating a microscope slide with silicon stopcock grease (Dow Corning High Vacuum Grease; Dow Corning Corp., Midland, MI, USA), placing the slide upon a $9 \mathrm{~cm} \times 9 \mathrm{~cm} \times 15 \mathrm{~cm}(\mathrm{~L} \times \mathrm{W} \times \mathrm{H})$ wooden block, and covering the block with one pollen bag. A naked microscope slide, a pollen trap sans pollination bag, was used as a control. The pollen traps were mounted at the height of developing sorghum panicles upon an iron pole driven into the ground in the middle of a furrow within an expansive plot of flowering sorghum and were left in place for 10 days until the anthers had dried and dropped, after which time the pollen traps were recovered, placed in labeled petri dishes, covered, and placed on the bench until they could be viewed. Six randomly selected fields from each slide were viewed by fluorescence microscopy through a compound microscope and micrographs captured with a digital camera. Pollen grains in each image of a $1.0 \times 1.5 \mathrm{~mm}$ field of view were counted and recorded. Means were separated using a multiway t-test with Bonferroni correction (LSMEANS procedure within GLM in SAS).

\subsection{Seed Yield}

The effect of bag material on self fertilization and yield was assessed by covering Pioneer 84G62-N271 panicles with HfT, SfT, or Paper pollination bags at boot and measuring yield of each panicle at the end of the season. The bags were used until the supply was expended and the remaining plants were covered with Paper bags. For this reason the numbers of bags used varied between treatments; Paper $=40$ bags, HfT $=32$ bags, and SfT $=27$ bags. The Paper bags were additionally covered with open mesh high tensile monofilament harvest bags (Midco Global, Inc., Kirkwood, MO, http://www.midcoglobal.com/product/midco-mesh-harvest-bags) to prevent bird damage. Means were separated as for pollen permeability.

\section{Results}

\subsection{Micro-Environment within Bags}

Bagging led to a considerable effect on the maximal daily temperatures about the developing panicles, but nighttime (minimum) temperatures were less affected. The range between the averaged maximal and minimal temperatures about the panicles covered by different bags is shown as color coded bands in Figure 1. Because there was little difference between measured temperatures inside and outside the bags, minimal bag temperatures were 


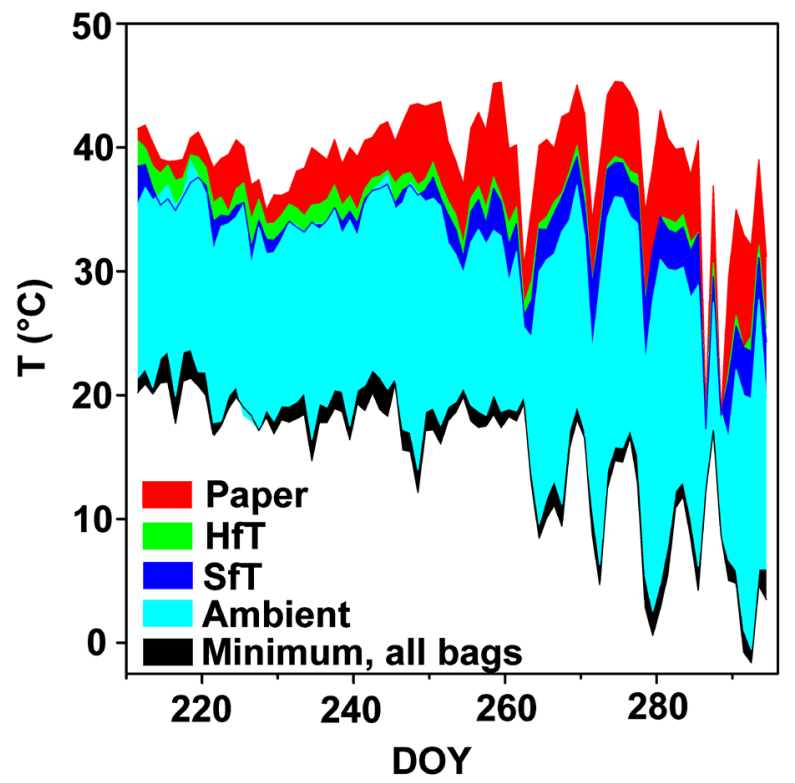

Figure 1. Minimal and maximal ambient temperatures and those within pollination bags fabricated from different materials. Red $=$ Paper, Green $=$ HfT, Blue $=$ SfT, and Cyan $=$ Ambient. Low temperatures under all bag materials were indistinguishable and thus averaged and are represented in Black. $n$ $=4$.

averaged and represented by a black band (Figure 1). Low temperatures within bags were slightly below ambient in all nearly all cases. Over the entire time the bags were in place, from anthesis to harvest, daily maximal temperatures increased in the order Air $<\mathrm{SfT}<\mathrm{HfT}<$ Paper.

Temperature increase as the maximal daily difference between the interior and ambient air temperatures, that is, the daily maximal $\left(\mathrm{T}_{\text {air }}-\mathrm{T}_{\mathrm{bag}}\right.$ ), exhibited a similar but much more pronounced pattern (Figure 2). The interior of Paper bags exhibited temperature increases of $10^{\circ} \mathrm{C}$ to $20^{\circ} \mathrm{C}$ above ambient. Differences in pollination bag temperatures were much reduced on DOY 254, 262, 286, and 288 because of overcast conditions, i.e., days with low solar. The differences between temperatures within pollination bags and ambient temperatures increased over the season as ambient air temperatures decreased. Differences between the Paper and the polyethylene bags were significant throughout the experiment $(\mathrm{Pt}<0.05)$.

Examination of the diurnal temperature regime within the bags (Figure 3(b)) on three consecutive clear days (Figure 3(a)) revealed a bi-modal increase in temperature pattern. Maximal temperature occurred in the midmorning when ambient temperatures were low and the sun low in the sky. As solar noon approached, temperature decreased and was followed by a minor elevation in temperature in the afternoon. Nighttime temperatures within all pollination bags were $2^{\circ}-3^{\circ}$ cooler than ambient. Bag material had no consistent differential effect on nighttime temperatures.

Moisture within the bags exhibited a bit more complex diurnal pattern but a bimodal pattern is discernable in all bag materials (Figure 3(c) and Figure 3(d)). The RH was lower in the Paper bags and was separable from the HfT during both day and night time (Figure 3(c)). Decreased RH in Paper was associated with elevated bag temperatures during the day but not at night. Dewpoints were highest in Paper and HfT and lower in the perforated SfT material $[($ Paper $=\mathrm{Hft})>\mathrm{SfT}]$.

\subsection{Pollen Permeability}

Paper and HfT similarly reduced pollen transmission to the glass slides (Figure 4). Slides covered with SfT bags allowed at least an order of magnitude more pollen to pass as compared to Paper and SfT. SfT only reduced pollen transmission to about a third of the naked slides used as controls.

One way ANOVA revealed a significant effect of bag type on number of seeds produced in the male sterile 


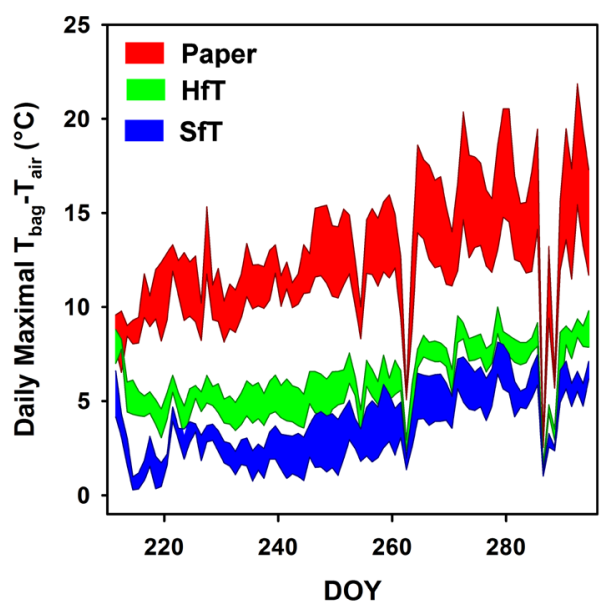

Figure 2. Maximal temperature increases above ambient temperatures under pollination bags fabricated from different materials. Red $=$ Paper, Green $=$ HfT, Blue $=$ SfT. Bands are average plus or minus SE. Differences were significant throughout most of the season $(\mathrm{Pt}<0.05) \mathrm{n}=4$.

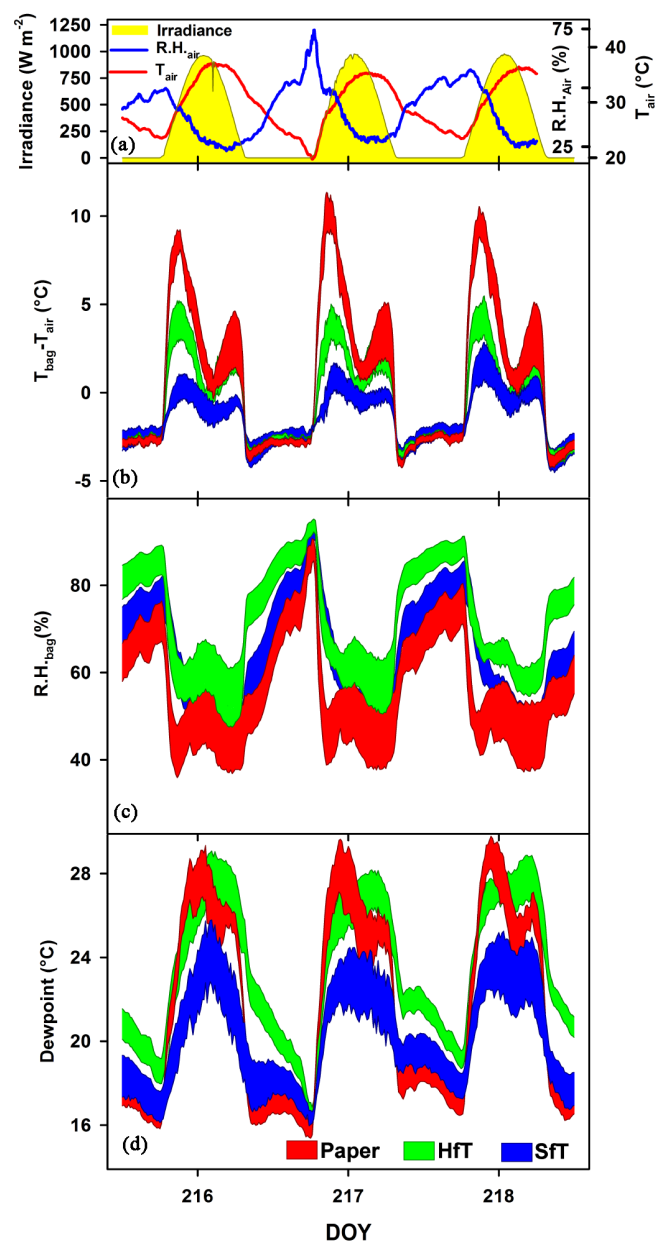

Figure 3. Diurnal ambient environmental conditions, and micro-environmental conditions within pollination bags over three consecutive days. (a) Ambient conditions; Incident solar irradiance (Yellow), ambient temperature (Red), and ambient RH (Blue); (b)-(d) Microenvironemntal conditions within bags. Bands are average values \pm SE $(n=4)$. Red = Paper, Green = HfT, Blue = SfT; (b) Difference in temperature within and outside of bags $\left(\mathrm{T}_{\mathrm{air}} \times \mathrm{T}_{\mathrm{bag}}\right)$; (c) Relative humidity and (d) dewpoints within bags. 


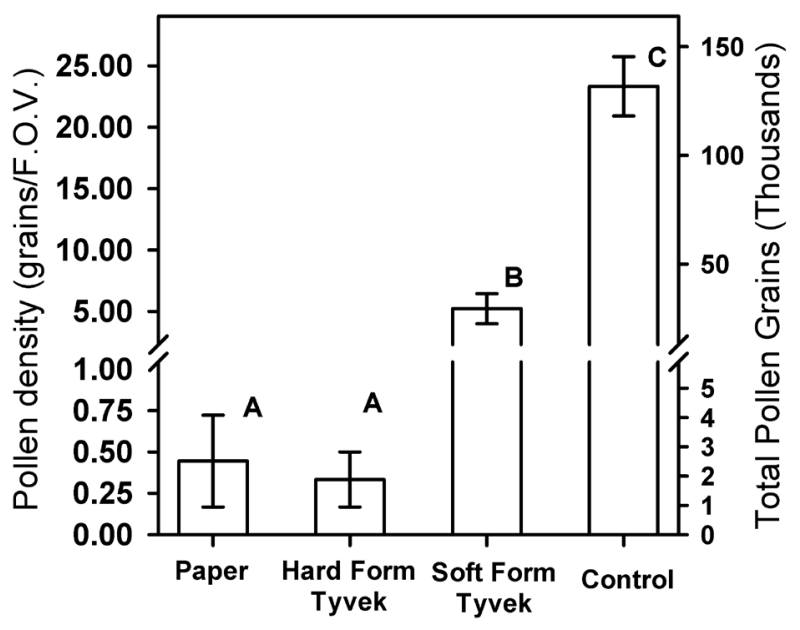

Bag Material

Figure 4. Pollen density on microscope slides coated with silicon stopcock grease as grains/field of view (left axis) and estimated total number of pollen grains within apparatus (right axis). Average $\pm \mathrm{SE}$ are shown $(\mathrm{n}=4)$.

plants $(\mathrm{P}<\mathrm{F}=0.047)$. While average numbers and mass of seeds increased in the order Paper $<\mathrm{HfT}<\mathrm{SfT}$ (Figure 5) the only statistically significant difference between these treatments was in the SfT. The seeds produced under the Paper and hard form Tyvek bags were generally restricted to the distal end of two or three panicles where 100 to 200 seeds were produced. Seed production under SfT was quite diffuse and occurred along the length of the panicles.

On three male sterile plants covered with HfT, seed heads had 100 - 120 seeds limited to the distal ends of the panicles (not shown). Only one of the forty-one Paper, 2\%, had 150 seeds at the distal end of the panicle. This was consistent with the panicles being bagged after flowering began. In the sorghum we used, flowering starts at the distal end of the inflorescence and proceeds towards the base of the panicle over the course of several days. It seems that the flowers matured and were fertilized over a weekend and the developing panicles were not discovered until the workers returned to the field. The possibility that the sewed upper seam of the HfT bags may have allowed some pollen through cannot be eliminated. This latter possibility seems unlikely given there was no pollen transmission difference between the Paper and HfT bags, and one Paper bag out of forty-one had about 150 seeds at the tip of the panicle. Likewise, some seed heads had a few $(5-25)$ seeds clustered about the base of the seed head, consistent with the bag not being well closed about the stem and allowing pollen to enter from below, or not covering a few flowers.

\subsection{Seed Yield}

The commercial hybrid plants self pollinated and the mean seed yield values for the different bag materials increased as: Paper $<$ HfT $<$ SfT (Figure 6). Differences were statistically non-significant $(\mathrm{Pt}>0.05$ ). Mean seed yield as mass per plant in Paper bagged individuals was nearly identical to that of HfT.

\section{Discussion}

"Bagging" plants, placing a fabric barrier between the reproductive structures and the environment, is done to collect pollen, control pollen exchange by insects or wind, and to control herbivory by insects or vertebrates. Bag materials have been studied for decades and have been made of muslin, micromesh, polyethylene, cellulose acetate, micropore acetate bread bags, and Paper [6]-[11]. Each of these materials exhibits unique advantages and disadvantages. Although new fabrics are continually being developed, sorghum breeders continue to use the traditional Paper bags, presumably because of low cost, ready availability, and adherence to standard practices that have long been in place. In the present work the microenvironment within novel spunbond polyethylene and brown Paper pollination bags was investigated. 


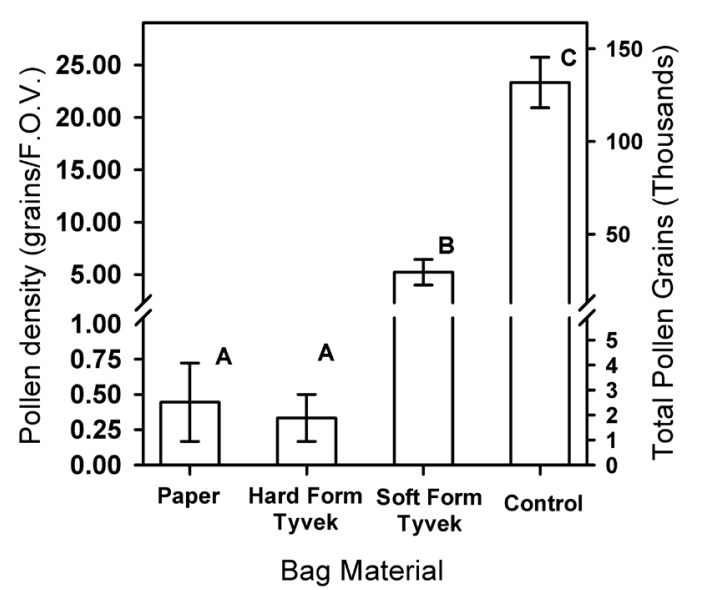

Figure 5. Seeds/panicle formed by male sterile (ATx623) sorghum plants covered by different bag materials. Average \pm SE are shown.

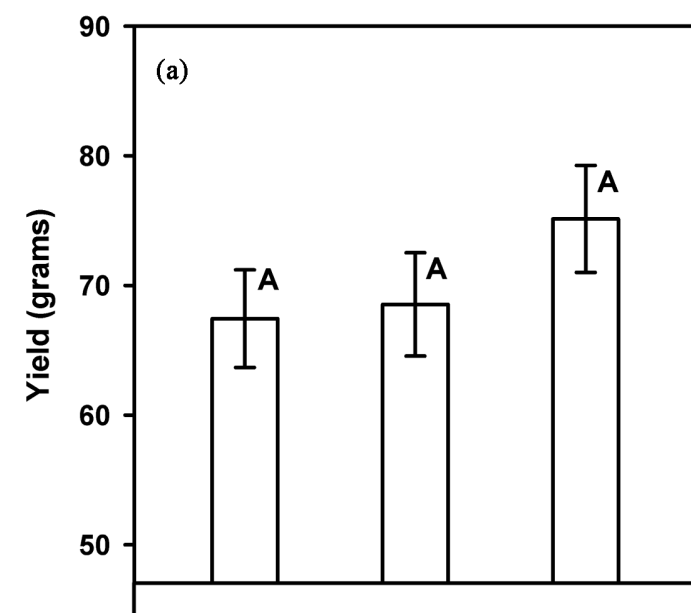

(b)

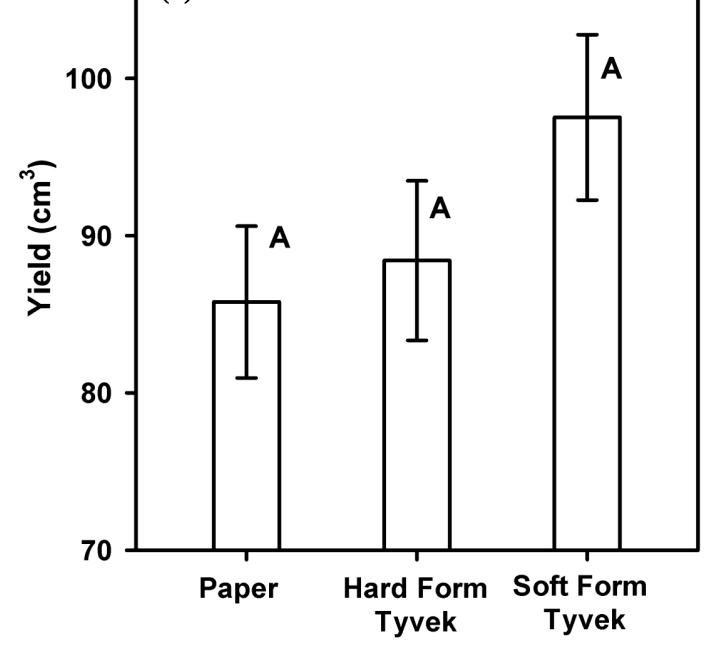

Bag Material

Figure 6. Yield in a commercial sorghum covered with pollination bags at boot and allowed to self pollinate. (a) Yield (g); (b) Yield $\left(\mathrm{cm}^{3}\right)$. Average \pm SE are shown. 
A considerable increase in temperature was measured within the brown Paper pollination bags throughout the season as compared to ambient temperatures. The daily temperature regime within the bags was probably affected by the bag orientation, and perhaps by the albedo and permeability of the bag materials. The bimodal diurnal pollination bag temperature profile (Figure 3(b)) is similar to that expected from the terrestrial solar heat loading of vertical cylinders. The bimodal pattern has been reported for pollination bags elsewhere, though the degree of heating especially in the present work is previously unreported [7]. The temperature increases that took place in the widely used Paper bags, especially as compared to the polyolefin bags, was unexpected. It is suspected that temperatures within such pollination bags could be much higher depending on the optical properties of the material. Conversely, this suggests that simply switching to white Paper bags could effectively moderate potential temperature increases. The current study was unable to detect a significant effect of bag material on seed yield within the selfing hybrid plants so, while bag temperature increases were remarkable, they are probably not a practical issue for most germplasm maintenance operations. Even if temperatures under Paper bags affected pollen development and viability, fertilization, and subsequent seed development; such temperature sensitivity of this trait would probably have been selected against over the course of hundreds of generations of breeding and even in germplasm maintenance operations given the ubiquitous use of Paper pollination bags.

Characterization of the optical properties, reflection and transmission, of the bag materials was beyond the scope of the objectives of this study and so they were not systematically investigated. Nevertheless, transmission of photosynthetically active radiation (PAR) through the bags was quickly estimated by simply holding a broadband PAR sensor within the bags at solar noon and subsequently removing it and measuring full sunlight (not shown). Both of the spun polyethylene bags used in this work transmitted about $30 \%$ of the incident solar radiation while the Paper bags transmitted only 6\%. Values for Tyvek reflectance in air are reported to be between 75\% - 90\% [12] [13]. The appearance of the male sterile ATx623 panicles differed between the Paper and Tyvek bags (not presented). Panicles from Paper were pale, almost white, while those from spun polyethylene bags were distinctively tan to brown. Light quality has long been known to elicit photomorphogenic responses in plants including effects on pigment production and secondary phenolic synthesis. Ultraviolet radiation is a small component of the terrestrial solar spectrum but exerts a disproportionate photomorphogenic effect on plants [13] [14]; and polyethylene transmits considerable UV radiation [15]. It remains unknown whether or how the radiation or temperature microenvironments within the bags may have led to the pigmentation differences, but it points to the potential for such effects on panicle development under pollination bags [9].

Humidity was clearly affected by temperatures within the bags so it is somewhat difficult to draw conclusions. Calculated dewpoints revealed that during the daytime less moisture was present within the SfT bags as compared to the other two materials. At times mold has been found on sorghum panicles covered with Paper and HfT pollination bags, especially when the plants were irrigated during pollination and seed filling (not presented). A bird resistant bag that closely approximates ambient temperature and light conditions while allowing moisture to freely pass might be useful for well irrigated field grown and greenhouse grown plants.

The pollen transmission of the SfT relative to the HfT and the Paper might exclude or at least limit its usefulness as a material for breeding operations (Figure 4 \& Figure 5). In the pollen traps, the pollen transmission was only reduced to $20 \%$ of the controls while seed production in the male sterile plants was reduced by $99 \%$ assuming a typical sorghum panicle produces about 2500 seeds [3]. The difference between seed reduction seems inconsistent with results from the pollen traps but the pollen traps were left in place for 10 days to insure that plants throughout the nursery were producing pollen and wind was suitable for pollen transmission to, and through the bags. With the male sterile ATx623, the pollen density in the air and the wind conditions may not have been ideal for transmission during the time the plants were flowering, though this was not investigated further. Both the pollen traps and the Atx623 bioindicator plants revealed that pollen were not totally excluded by the perforated SfT material. The material may still be suitable for applications in which plants are allowed to self pollinate, however. Considerable pollen is generated by the sorghum flowers. Without pollination bags, maximal reported outcrossing values are $80 \%$ but are generally on the order of $5 \%-15 \%$ [16]. Containing the pollen produced within the bags and allowing the plants to self pollinate might effectively eliminate outcrossing in germplasm maintenance or in greenhouse operations where wind velocities are lower and where all panicles are covered.

Both the Paper and HfT bags eliminated much of the pollen transmission to the pollen traps and to developing panicles in the male sterile ATx623 plants. In ATx623, some panicles in both the Paper and HfT bags two pani- 
cles produced numerous seeds at the distal end of the panicle. This is consistent with the inflorescence being bagged after the flowers were receptive to fertilization especially since this plant flowers from the distal end (top) to the proximal end (bottom) of the panicle over the course of several days. Even though both Paper and HfT bags exhibited seed production, the possibility of pollen passing through a sewn seam in the HfT could not be eliminated. So, data from these individuals were included in the analysis and presentation. Some panicles from the Paper and HfT bagged plants were found with a few (5 - 20) seeds at the base of the panicles. This is consistent with either the bags not covering the flowers or not being well sealed around the stems allowing pollen to enter. These were included in the analysis as well. Our approach to the data may have failed to reveal such potential differences in the effectiveness of both the Paper and HFT bags, which could exist. Interpretation of the results presented herein should be done with this in mind.

\section{Conclusions}

Bagging sorghum panicle is a labor intensive exercise. Even with a concerted daily effort in a well organized field, operation flowering panicles can be missed allowing upper flowers to be pollinated. Bags can be improperly placed or not sealed about the stem tightly and allow pollen to enter from the bottom of the bag. To minimize chances for potentially collecting cross-pollinated seed, all non-bagged panicles should be removed from the field. The upper $20 \%$ or so of each panicle can be removed before threshing if there is concern about the field labor not bagging the panicles in a timely manner. The bottom $5 \%-10 \%$ of each panicle can be hand stripped as well.

Perhaps most importantly, the bird-resistant spun polyethylene bags reduce the need for laborers to repeatedly walk the field to cover plants with additional bags as bird damage occurred during seed development, exclude pollen as well as conventional Paper bags, and result in seed yields indistinguishable from Paper. These bags are easily made to different dimensions so that they can be adapted to sorghum with large open panicles such as broom sorghums [17]. The bags used in these experiments induce micro-environmental changes that should be considered when designing experiments, though again, these have no effect upon seed yield. Hot pin perforated polyolefin bags may be suitable for greenhouse applications where mold is a concern and where ambient air velocities are low or in field settings where pollen production by the panicles being covered is high.

\section{Acknowledgements}

We thank Dr. Lan Liu-Gitz for helpful discussions and suggestions through the course of this experiment and Cody Byars for his technical assistance. We gratefully acknowledge the efforts of Dr. John Stout for his selfless efforts to both maintain the ARS weather station and to make the data publicly accessible. This research was supported in part by the Ogallala Aquifer Program, a consortium between USDA-Agricultural Research Service, Kansas State University, Texas A \& M AgriLife Research, Texas A\&MAgriLife Extension Service, Texas Tech University, and West Texas A \& M University.

\section{References}

[1] Dahlberg, J., Berenji, J., Sikora, V. and Latkovic, D. (2011) Assessing Sorghum [Sorghum bicolor (L.) Moench] Germplasm for New Traits: Food, Fuels \& Unique Uses. Maydica, 56, 85-92.

http://eprints.icrisat.ac.in/7455/1/Maydica_56_1750_85-92_2011.pdf

[2] Ormerod, S.J. and Watkinson, A.R. (2000) Editor's Introduction: Birds and Agriculture. Journal of Applied Ecology, 37, 699-705. http://dx.doi.org/10.1046/j.1365-2664.2000.00576.x

[3] Gitz, D., Baker, J., Xin, Z., Lascano, R., Burke, J. and Duke, S. (2013) Research Note: Bird-Resistant Pollination Bags for Sorghum Breeding and Germplasm Maintenance. American Journal of Plant Sciences, 4, 571-574. http://dx.doi.org/10.4236/ajps.2013.43074

[4] Frederiksen, R.A. and Miller, F. (1972) Proposal for Release and Increase ATx622, BTx622, ATx623, BTx623, ATx624, BTx624. TAES Form 96-72: Seed Release Committee of the Texas Agricultural Experiment Station College Station.

[5] Lawrence, M.G. (2005) The Relationship between Relative Humidity and the Dewpoint Temperature in Moist Air: A Simple Conversion and Applications. Bulletin of the American Meteorological Society, 86, 225-233. http://dx.doi.org/10.1175/BAMS-86-2-225

[6] Neal, P.R. and Anderson, G.J. (2004) Does the “Old Bag” Make a Good “Wind Bag”?: Comparison of Four Fabrics 
Commonly Used as Exclusion Bags in Studies of Pollination and Reproductive Biology. Annals of Botany, 93, 603-607. http://dx.doi.org/10.1093/aob/mch068

[7] Ball, S.T., Campbell, G.S. and Konzak, C.F. (1992) Pollination Bags Affect Wheat Spike Temperature. Crop Science, 32, 1155-1159. http://dx.doi.org/10.2135/cropsci1992.0011183X003200050019x

[8] McGranahan, G.H., Voyiatzis, D.G., Catlin, P.B. and Polito, V.S.I. (1994) High Pollen Loads Can Cause Pistillate Flower Abscission in Walnut. Journal of the American Society for Horticultural Science, 119, 505-509. http://journal.ashspublications.org/content/119/3/505.short

[9] Pickering, R.A. (1982) The Effect of Pollination Bag Type on Seed Quality and Size in Hordeum: Inter-and Intraspecific Hybridization. Euphytica, 31, 439-449. http://dx.doi.org/10.1007/bf00021661

[10] Wyatt, R., Broyles, S.B. and Derda, G.S. (1992) Environmental Influences on Nectar Production in Milkweeds (Asclepiassyriaca and A. exaltata). American Journal of Botany, 79, 636-642. http://dx.doi.org/10.2307/2444879

[11] del Río, C. and Caballero, J.M. (1999) A New Bag for Olive Pollination Studies. International Society for Horticultural Science, III International Symposium on Olive Growing. Acta Horticulturae, 474, 233-236. http://www.actahort.org/books/474/474_46.htm

[12] Stoll, S.P. (1996) An Investigation of the Reflective Properties of Tyvek Papers and Tetratex PTFE Film. Physics Department, Brookhaven National Laboratory, PHENIX Note \#245. http://www.phenix.bnl.gov/WWW/publish/ssato/2001/upg2001oct/pdf/1019_2001_sean_phenix_tech_note_245.pdf

[13] Rozema, J., van de Staaij, J., Björn, L.O. and Caldwell, M. (1997) UV-B as an Environmental Factor in Plant Life: Stress and Regulation. Trends in Ecology \& Evolution, 12, 22-28. http://dx.doi.org/10.1016/S0169-5347(96)10062-8

[14] Jordan, B.R. (2002) Review: Molecular Response of Plant Cells to UV-B Stress. Functional Plant Biology, 29, 909916. http://dx.doi.org/10.1071/FP02062

[15] Kataoka, I. and Beppu, K. (2004) UV Irradiance Increases Development of Red Skin Color and Anthocyanins in "Hakuho” Peach. Hort Science, 39, 1234-1237.

[16] Pedersen, J.F., Toy, J.J. and Johnson, B. (1998) Natural Outcrossing of Sorghum and Sudangrass in the Central Great Plains. Crop Science, 38, 937-939. http://dx.doi.org/10.2135/cropsci1998.0011183X003800040009x

[17] Smith, D.C. and Mehlenbacher, S.A. (1994) Use of Tyvek Housewrap for Pollination Bags in Breeding Hazelnut (Corylus avellana L.). Hortscience, 29, 918. 
Scientific Research Publishing (SCIRP) is one of the largest Open Access journal publishers. It is currently publishing more than 200 open access, online, peer-reviewed journals covering a wide range of academic disciplines. SCIRP serves the worldwide academic communities and contributes to the progress and application of science with its publication.

Other selected journals from SCIRP are listed as below. Submit your manuscript to us via either submit@scirp.org or Online Submission Portal.
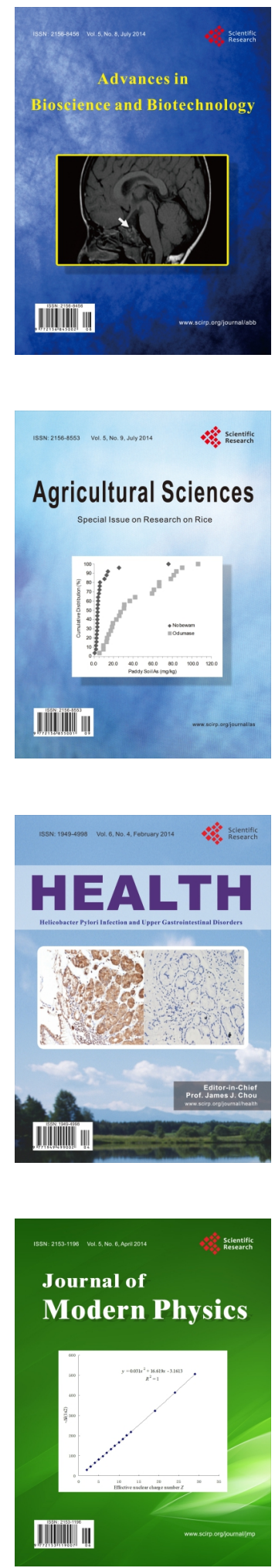
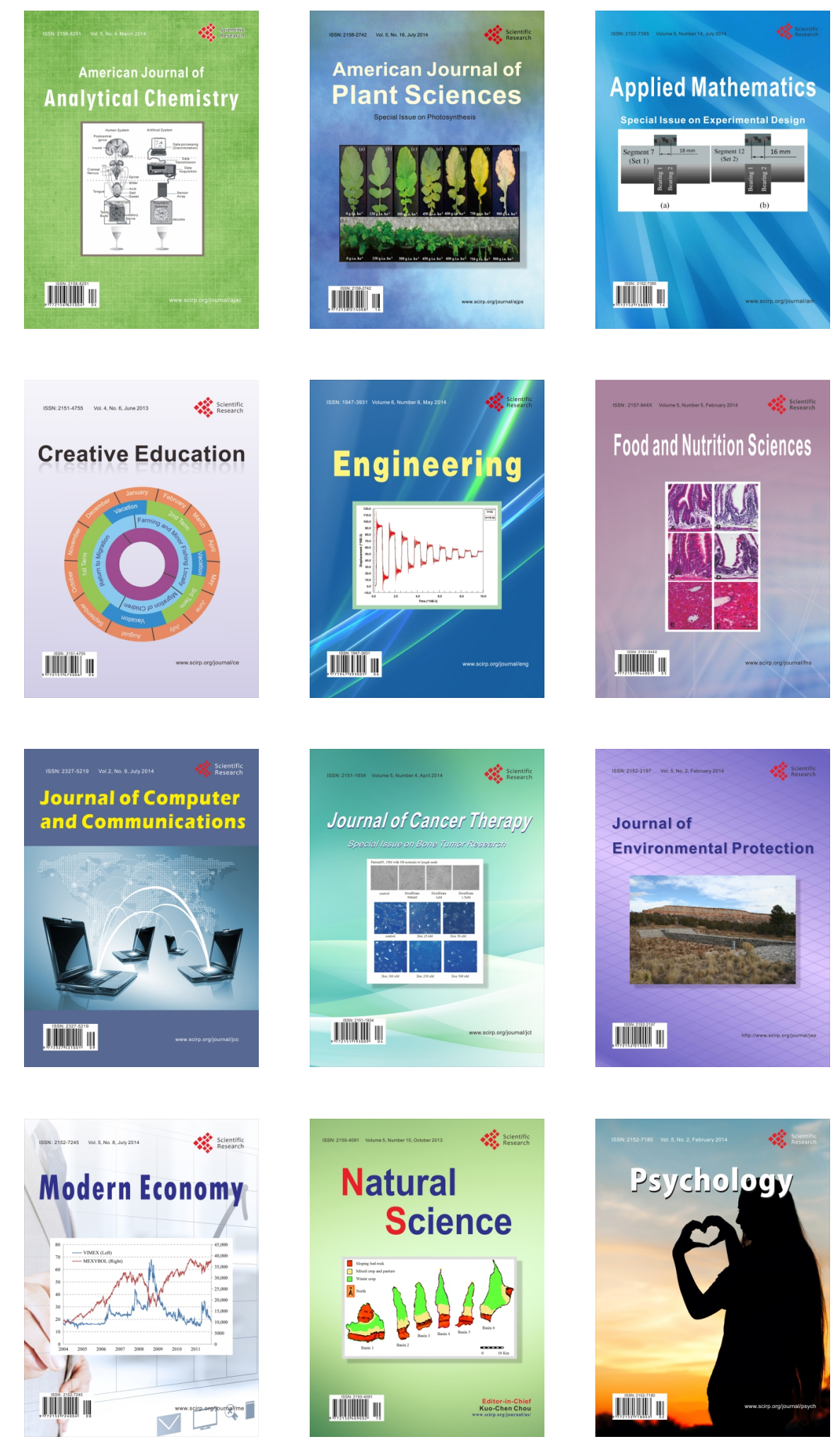